\title{
O PODER E A GLÓRIA DE EMILY DICKINSON
}

Fernanda Mourão

Doutoranda em Letras - Estudos Literários

\begin{abstract}
RESUMO
Com base nas teorias de Walter Benjamin e Maurice Blanchot, este trabalho procura pensar a obra de Emily Dickinson pelo viés da publicação e da fama da figura do autor a partir da experiência de leitura, tradução e apresentação, ao final do texto, de dez poemas da escritora que trazem à tona justamente essas questões.
\end{abstract}

\section{PALAVRAS-CHAVE}

Poesia, escrita, experiência, tradução, publicação

\begin{abstract}
Daí a riqueza e a miséria, o orgulho e a humildade, a extrema divulgação e a extrema solidão do nosso trabalho literário, que tem pelo menos o mérito de não desejar o poder nem a glória.
\end{abstract}

Maurice Blanchot

É no mínimo intrigante o caso da escritora cuja obra se confunde com a própria vida, cuja vida nos lega nada mais, nada menos, que sua experiência com a literatura. Se quase nada se sabe sobre a figura Emily Dickinson, se para o mundo de sua época sua vida passou em branco, foi na branca noite da escrita que ela viveu, e hoje é difícil figurar a mulher fora de sua experiência literária.

De fato, além do pouco sabido sobre sua vida pessoal, a própria escrita de Emily Dickinson não nos permite fazer muitas aproximações. Se Walt Whitman, seu contemporâneo, é o poeta que rompe as fronteiras do espírito norte-americano com seu "grito bárbaro" e escreve a epopeia de sua época, o gênio da escritora não é de nenhuma maneira 
épico, humanitário, nacionalista ou público, mas, ao contrário, lírico, pessoal, intensamente concentrado, e quase secreto.

A partir da "experiência Emily", da leitura de sua obra, venho traduzindo seus poemas e agora, curiosamente, apresento aqui uma seleção daqueles que nos dizem exatamente de sua preocupação com a questão da fama. O fato é que, se Whitman lança seu livro como um manifesto e passa toda sua vida reeditando e reafirmando aquela obra que seria sua grande missão e contribuição à humanidade, Emily nada publica - jamais seria conhecida por seus contemporâneos pois que já era, desde sempre, uma contemporânea do futuro. Disso ela parecia saber, pois, ainda que alguma vez tivesse considerado tal possibilidade, certamente renunciara ao poder e à glória da notoriedade em favor de uma total dedicação à escrita quando inicia a correspondência com aquele que lhe aconselharia - temendo a recepção do público - adiar a publicação:

Sorrio quando o senhor sugere que eu adie a "publicação" - estando isto tão longe do meu pensamento, como o Firmamento dos Peixes -

Se a Fama me pertencesse, eu não conseguiria fugir a ela - se assim não fosse, o mais longo dos dias seria gasto em seu encalço - e eu perderia a aprovação do meu Cão - assim - minha Ordem-Descalça é melhor - ${ }^{1}$

De fato, Emily Dickinson nada publica. Apenas meia dúzia de poemas seus são publicados esparsamente, por amigos, à revelia da escritora. O mundo literário de sua época não tomaria conhecimento de sua existência. Não obstante, ela escreve. Como André ComteSponville, ao falar sobre sua relação com a poesia: "Escrevi muitos [poemas], e nunca parei de todo. A poesia me parece o essencial do que a linguagem pode dizer e ser portadora. Mas escrever é outra coisa; e publicar ainda outra." 2

Trancada no quarto, ela escreve. A partir dos 28 anos, passa a vestir-se exclusivamente de branco e a conversar com os amigos, nas raras ocasiões em que os recebia, somente através da porta entreaberta. ${ }^{3}$ Consta que Emily, ao morrer, deixa, nas gavetas daquele mesmo quarto onde viveu reclusa em sua escrita, 1.775 poemas, 900 dos quais cuidadosamente copiados a tinta em sessenta pequenos volumes, ou "fascículos", como foram chamados - folhas de papel meticulosamente dobradas e costuradas - seu livro por vir. Grande parte do restante, e muitos outros escritos ainda, encontravam-se em papéis de diferentes formas e tamanhos, envelopes usados, páginas de cadernos e folhas de receitas.

\footnotetext{
${ }^{1}$ DICKINSON. Selected letters, p.174. (Carta 265).

${ }^{2}$ COMTE-SPONVILLE. O amor a solidão, p. 113.

${ }^{3}$ CODY. After great pain: the inner life of Emily Dickinson, p.19-20.
} 
Mas por que não publica Emily Dickinson? Por que motivos passa toda a vida enviando sua produção poética a um tutor que, apesar de reconhecer a força daquela escrita, não deixaria nunca de tentar corrigi-la? Por que escolhe como interlocutor exatamente aquele que se colocaria entre ela e o público, e justamente por temer sua recepção?

Porque Emily não escreve para Higginson. Sabia que não era lida por ele; mais ainda, sabia da inutilidade de se escrever para ser lida em qualquer circunstância, pois que, lendo, o público apenas lê a si próprio. Como Blanchot, sabia que

o autor que escreve especialmente para um público, na realidade, não escreve: é esse público que escreve, e, por essa razão, esse público não pode ser mais leitor; a leitura é apenas em aparência, no fundo ela é nula. Daí a insignificância das obras feitas para serem lidas - ninguém as lê. ${ }^{4}$

Realmente, mesmo um quarto de século após sua morte, com parte de sua produção publicada, a crítica literária americana descreve a escritora como uma mulher excêntrica, solteirona, isolada em casa, inapreensível. O público, este tem então sua opinião formada antes mesmo de se interessar pelo que escrevera Emily. Mais tempo ainda, setenta anos após o falecimento da escritora e com todos os seus poemas pela primeira vez publicados conforme o original (as publicações anteriores sofreram “revisões"), Emily finalmente poderia ser lida. Mas, assim se pergunta Augusto Joaquim : “quem se disporia a escutá-la e a lê-la no que ela escrevera?" 5

Não. Mesmo hoje não podemos dizer que a publicação de seus poemas tenha resultado em sua leitura. Pois que "publicar não é fazer-se ler, nem dar a ler o que quer que seja. O que é público não tem precisamente necessidade de ser lido; é sempre já conhecido, antecipadamente, de um conhecimento que sabe tudo e não quer saber nada". 6

Emily parecia disso saber, e também, como Blanchot ainda, do perigo de se procurar o leitor no público, como Orfeu a procurar Eurídice nos infernos, orientando-se para uma palavra que ninguém ouvirá. Por isso escreve em silêncio, no "movimento de uma palavra desapossada e desenraizada, que à pretensão de dizer tudo prefere nada dizer e, sempre que diz alguma coisa mais não faz que designar o nível abaixo do qual é preciso descer ainda, se se quer começar a falar". 7

\footnotetext{
${ }^{4}$ BLANCHOT A parte do fogo, p. 297.

${ }^{5}$ JOAQUIM. Como começam as cidades. Prefácio a Dickinson, Emily Augusto Joaquim, p. 10.

${ }^{6}$ BLANCHOT. O livro por vir, p. 258.

${ }^{7}$ BLANCHOT. O livro por vir, p. 261.
} 
Assim, trancada em seu quarto, vestida de branco, essa mulher escreve. É apesar de tudo isso que ela escreve, e é pela mesma causa que a lemos - ou não.

É contra uma palavra indefinida e incessante, sem começo nem fim, contra ela mas também com a sua ajuda, que o autor se exprime. É contra o interesse público, contra a curiosidade distraída, instável, universal e omnisciente, que o leitor acaba por ler, emergindo penosamente dessa primeira leitura que antes de ter lido já leu: lendo contra ela mas mesmo assim através dela. O leitor e o autor participam, um numa escuta neutra, o outro numa palavra neutra, que gostariam de suspender por momentos para lhe substituírem uma expressão mais bem ouvida. ${ }^{8}$

É assim que Emily dedica toda a sua vida a uma produção poética incessante, à exigência de uma obra que se faria presente mesmo sem o encorajamento da aclamação pública. Pois se não se escreve ou publica para ser lido, e muito menos pela pequena glória do renome e da fama - Blanchot nos lembra que o mais célebre dos escritores é menos nomeado que o locutor diário da rádio! -, somente uma necessidade da própria obra pode fazer com que ela seja.

Penso que o escritor não deseja nada para si, nem para sua obra. Mas a necessidade de publicação - quer dizer de aceder à existência exterior, a essa divulgação-dissolução que as nossas grandes cidades proporcionam pertence à obra, como uma lembrança do movimento de onde ela vem (...). ${ }^{9}$

Perguntado sobre o que pede à escrita, e sobre o que a escrita lhe dá, Comte-Sponville responde: "Peço-lhe cada vez menos e ela me dá cada vez menos. (...) Quanto mais se liberta de si, menos a escrita tapa o real; quanto menos nos enganamos sobre ela, menos ela nos engana sobre o mundo."10

Emily Dickinson não se enganou com a pequena glória da literatura. "Existence has overpowered Books" - disse ela certa vez. Como Blanchot, não desejou nada para si, pois sabia que, antes de possui-la, "o escritor pertence à obra, mas o que lhe pertence é somente um livro, um amontoado mudo de palavras estéreis, o que há de mais insignificante no mundo". ${ }^{11}$ Sabia que não seria esse amontoado de palavras estéreis o que the traria a Imortalidade; esteve todo o tempo "votada ao erro de um empreendimento necessariamente um pouco mais longo que a sua vida". ${ }^{12} \mathrm{O}$ Livro já existia, desde sempre. A verdadeira Glória

\footnotetext{
${ }^{8}$ BLANCHOT. O livro por vir, p. 258.

${ }^{9}$ BLANCHOT. O livro por vir, p. 259.

${ }^{10}$ COMTE-SPONVILLE. O amor a solidão, p.109.

${ }^{11}$ BLANCHOT. O espaço literário, p. 13

${ }^{12}$ BLANCHOT. O livro por vir, p. 103.
} 
daquela que apenas uma vez deixou-se capturar em imagem, por um daguerreótipo, seria justamente a glória do desaparecimento, da renúncia, para dar lugar a essa Obra.

É assim que sua "carta ao mundo" se escreve como exigência, como resultado da passividade daquela mulher que renuncia à vida em favor da obra - "Eu não posso viver com Você - /Isso seria Vida -". ${ }^{13}$ Ou, melhor, que vive em sua obra; obra que traz em si essa vida - a lei de sua pervivência. A publicação, assim, mais cedo ou mais tarde se daria, também como exigência. Quanto a nós, continuamos sendo chamados pela sua letter, e traduzir pode ser uma forma de fazer soprar essa vida, de deixar falar essa voz que exige seu retorno ao rumor incessante do exterior.

A história das grandes obras de arte conhece sua descendência a partir de suas fontes, sua estruturação na época do artista e o período, em princípio eterno, de sua pervivência nas gerações seguintes. Esta última, quando ocorre, chama-se glória. As traduções que são mais que meras mediações nascem quando, em sua pervivência, a obra alcança a época de sua glória. Elas antes devem sua existência a esta glória do que a promovem, como supõem os maus tradutores. Nelas, a vida do original, em renovação constante, alcança um outro e mais extenso desdobramento. ${ }^{14}$

\section{POEMAS}

67

Success is counted sweetest

By those who ne'er succeed.

To comprehend a nectar

Requires sorest need.

Not one of all the purple Host

Who took the Flag today

Can tell the definition

So clear of Victory

As he defeated - dying -

On whose forbidden ear

The distant strains of triumph

Burst agonized and clear!

O Sucesso é tão mais doce

Aos que nunca o provaram.

Compreender um néctar

Requer sofrimento raro.

\footnotetext{
${ }^{13}$ DICKINSON. The complete poems of Emily Dickinson, p.317-318. (poema 640).

${ }^{14}$ BENJAMIN. A tarefa do tradutor, p.viii.
} 
Nem o que na Multidão

Ergue a Bandeira agora

Pode dar definição

Mais clara da Vitória

Que o derrotado - a morrer -

Em cujo ouvido distante

A sonora canção do triunfo

Ecoa agônica, gritante!

288

I'm Nobody! Who are you?

Are you - Nobody - Too?

Then there's a pair of us!

Don't tell! they'd advertise - you know!

How dreary - to be - Somebody!

How public - like a Frog -

To tell one's name - the livelong June -

To an admiring Bog!

Eu sou Ninguém! Quem é você?

Você é - Ninguém - também?

Então somos dois - Não conte!

Ou seremos notícia - veja bem!

Que medo - ser - Alguém!

Tão público - como a Rã -

Coachar seu nome o Verão todo -

Tendo o Brejo como fã!

349

I had the Glory - that will do -

An Honor, Thought can turn her to

When lesser Fames invite -

With one long "Nay" -

Bliss' early shape

Deforming - Dwindling - Golfing up -

Time's possibility.

Tive a Glória - é o bastante -

Honra, pode torná-la a Mente

Se Famas menores chamarem -

Com um longo "Mas" -

A forma primeira da Alegria

Deformando - Diminuindo - Devorando -

O Tempo assim faz. 
Publication - is the Auction

Of the Mind of Man -

Poverty - be justifying

For so foul a thing

Possibly - but We - would rather

From Our Garret go

White - Unto the White Creator -

Than invest - Our Snow -

Thought belong to Him who gave it -

Then - to Him Who bear -

Its Corporeal illustration - Sell

The Royal Air -

In the Parcel - Be the Merchant

Of the Heavenly Grace -

But reduce no Human Spirit

To Disgrace of Price -

Publicação - eis o Leilão

Da Consciência Humana -

Pobreza - o motivo

Para tamanha infâmia

Talvez - mas - antes

De meu Quarto sair

Branca - para o Branco Criador -

Que minha Neve - investir -

A Mente pertence Àquele, que a deu Depois - ao que a sustenta -

E a Corpórea Inteligência - Vende

O Ar Real -

No Lote - seja o Negociante

Da Graça Celeste -

Mas não reduza uma Alma Humana

À Desonra do Lance -

713

Fame for Myself, to justify,

All other Plaudit be,

Superfluous - an incense

Beyond Necessity -

Fame for Myself to lack - Although

My Name be else Supreme -

This were an Honor honorless -

A futile Diadem - 
Fama, para Mim, comprova

Ser todo Aplauso

Em Vão - um incenso

Maior que a Precisão -

Fama, para Mim, inútil -

Embora meu Nome reine -

Uma Honra infame -

Um Diadema fútil -

\section{0}

The Beggar at the Door for Fame

Were easily supplied

But Bread is that Diviner thing

Disclosed to the denied

O Pedinte à Porta da Fama

Seria facilmente atendido

Mas Pão é coisa mais Divina

Dada ao excluído

\section{5}

Fame is the one that does not stay Its occupant must die

Or out of sight of estimate

Ascend incessantly -

Or be that most insolvent thing

A Lightning in the Germ -

Electrical the embryo

But we demand the Flame

Fama é aquela que não demora -

Seu ocupante deve morrer

Ou longe de estimativas

Constantemente ascender -

Tem algo de devedor

Um Raio em seu Germe -

Eletricidade embrionária

Quando queremos Fulgor

1531

Above Oblivion's Tide there is a Pier And an effaceless "Few" are lifted there Nay - lift themselves - Fame has no Arms And but one smile - that meagres Balms - 
Acima da Maré do Esquecimento há um Cais

"Poucos" até lá são içados -

Não! - sobem sozinhos - Fama não tem Braços -

Tem um só sorriso - Bálsamo escasso -

1660

Glory is that bright tragic thing

That for an instant

Means Dominion -

Warms some poor name

That never felt the Sun,

Gently replacing

In oblivion -

Glória é aquilo trágico e radiante

Que por um instante

É Domínio -

Aquece algum pobre nome

Que nunca experimentou o Sol,

E gentilmente o recoloca

No Limbo -

1763

Fame is a bee.

It has a song -

It has a sting -

Ah, too, it has a wing.

Fama é uma abelha.

Tem uma música -

Possui um ferrão -

E asas! - como não?

\section{ABSTRACT}

Based on Walter Benjamin's and Maurice Blanchot's theories, among others, this paper intends to think Emily Dickinson's work considering the questions of publication and the authors' fame, departing from the experience of reading, translating and presenting, at the end of this text, ten of Dickinson's poems which deal exactly with such issues.

\section{KEYWORDS}

Poetry, writing, experience, translation, publication 


\section{REFERÊNCIAS}

BENJAMIN, Walter. A tarefa do tradutor. 2. ed. rev. Trad. Karlheinz Bark e equipe. Rio de Janeiro: Instituto de Letras/UERJ, [s. d.]. p. v-xii. (Cadernos do Mestrado).

BLANCHOT, Maurice. O livro por vir. Trad. Maria Regina Louro. Lisboa: Relógio d'Água, 1984.

BLANCHOT, Maurice. O espaço literário. Trad. Alvaro Cabral. Rio de Janeiro: Rocco, 1987.

BLANCHOT, Maurice. A parte do fogo. Trad. Ana Maria Scherer. Rio de Janeiro: Rocco, 1997.

CODY, John. After great pain: the inner life of Emily Dickinson. Cambridge: Harvard University Press, 1971.

COMTE-SPONVILLE, André. $O$ amor a solidão. Trad. Eduardo Brandão. São Paulo: Martins Fontes, 2006.

DICKINSON, Emily. The complete poems of Emily Dickinson. Ed. Thomas H. Johnson. Boston/New York/London/Toronto: Litle, Brown and Company, 1960.

DICKINSON, Emily. Selected letters. Ed. Thomas H. Johnson. Cambridge/London: The Belknap Press of Harvard University Press, 1986.

JOAQUIM, Augusto. Prefácio - Como começam as cidades. In: DICKINSON, Emily. Bilhetinhos com poemas. Trad. Ana Fontes. Colares: Colares Editora, 1995. 